\title{
Incidence and time course of extrapyramidal symptoms with oral and long-acting injectable paliperidone: a posthoc pooled analysis of seven randomized controlled studies
}

\author{
This article was published in the following Dove Press journal: \\ Neuropsychiatric Disease and Treatment \\ 19 September 2013 \\ Number of times this article has been viewed
}

\section{Srihari Gopal' \\ Yanning Liu' \\ Larry Alphs ${ }^{2}$ \\ Adam Savitz' \\ Isaac Nuamah' \\ David Hough'}

'Janssen Research and Development, LLC, Raritan, ${ }^{2}$ Janssen Scientific Affairs, LLC, Titusville, NJ, USA
Correspondence: Srihari Gopal Janssen Research and Development, LLC, I I 25 Trenton-Harbourton Rd,

Titusville, NJ 08560, USA

Tel +l 6097302436

Email sgopal2@its.jnj.com
Background: The purpose of this study was to compare incidence rates and time course of extrapyramidal symptom (EPS)-related treatment-emergent adverse events (TEAEs) between oral and long-acting injectable (LAI) paliperidone.

Methods: The analysis included pooled data (safety analysis set, 2,256 antipsychotic-treated and 865 placebo-treated patients with schizophrenia) from seven randomized, double-blind, placebo-controlled paliperidone studies (three oral [6 weeks each] and four LAI [9-13 weeks]) and assessed comparable doses (oral, 3-15 mg; LAI, 25-150 mg eq. [US doses 39-234 mg]). We summarized incidence rates and time of onset for EPS-related TEAE, categorized by EPS group terms, ie, tremor, dystonia, hyperkinesia, parkinsonism, and dyskinesia, and use of anti-EPS medication. Mean scores over time for the Abnormal Involuntary Movement Scale (AIMS, for dyskinesia), Barnes Akathisia Rating Scale (BARS, for akathisia), and Simpson Angus Rating Scale (SAS, for parkinsonism) were graphed.

Results: Incidence rates for all categories of spontaneously reported EPS-related TEAEs except for hyperkinesia, were numerically lower in pooled LAI studies than in pooled oral studies. Highest rates were observed in the first week of paliperidone-LAI (for all EPS symptoms except dyskinesia) and oral paliperidone treatment (except parkinsonism and tremor). Anti-EPS medication use was significantly lower in LAI $(12 \%)$ versus oral studies $(17 \%, P=0.0035)$. Mean values for EPS scale scores were similar between LAI and oral treatment at endpoint, and no dose response was evident. Mean reductions (standard deviation) from baseline to endpoint in EPS scale scores were larger for LAI (AIMS, -0.10 [1.27]; BARS, -0.09 [1.06]; SAS, -0.04 [0.20]) versus oral studies (AIMS, -0.08 [1.32]; BARS, -0.03 [1.24]; SAS, 0.0 [0.23]). These changes favored LAI for BARS $(P=0.023)$ and SAS $(P<0.0001)$, but not for AIMS $(P=0.49)$, at endpoint for the studies.

Conclusion: In this posthoc descriptive analysis, incidence rates of spontaneously reported EPS-related TEAEs were numerically lower following approximately 90 days of exposure with LAI and approximately 40 days with oral paliperidone at comparable doses.

Keywords: antipsychotic agents, extrapyramidal symptoms, long-acting injectable, movement disorder, second-generation

\section{Introduction}

Extrapyramidal symptoms (EPS), which include a wide variety of movement disorders, such as parkinsonism, dystonia, dyskinesia, and akathisia, are a major class of adverse effects associated with antipsychotic medications. ${ }^{1,2}$ Minimizing the incidence 
of EPS is important from clinician, patient, and family perspectives, and important for treatment adherence. ${ }^{3}$ All dopamine $\mathrm{D}_{2}$ receptor antagonists, including paliperidone, have the potential to cause EPS via their ability to influence nigrostriatal dopaminergic transmission. ${ }^{3-5}$ Although secondgeneration antipsychotics are associated with a reduced risk of EPS-related treatment-emergent adverse events (TEAEs) compared with the first-generation antipsychotics, ${ }^{2,6-9}$ at higher doses, the risk for EPS-related TEAEs increases, particularly for akathisia. ${ }^{1,10}$

Paliperidone palmitate, the long-acting injectable (LAI) form of paliperidone, is approved for once monthly intramuscular injection. ${ }^{11}$ Because doses of paliperidone-LAI can be expressed both in terms of milligram equivalents (mg eq.) of the pharmacologically active fraction, ie, paliperidone, and in milligrams of paliperidone-LAI, the doses expressed as paliperidone-LAI 50, 100 and $150 \mathrm{mg}$ eq. equate to 78, 156, and $234 \mathrm{mg}$, respectively, of paliperidone-LAI. The recommended treatment regimen for paliperidone-LAI includes an initiation regimen of $150 \mathrm{mg}$ eq. on day 1 and $100 \mathrm{mg}$ eq. on day 8 (both in the deltoid muscle), ${ }^{12}$ followed by monthly deltoid or gluteal injections within the recommended maintenance range (25-150 mg eq.). ${ }^{12}$ The use of higher doses to initiate treatment ("loading doses") with antipsychotics is limited to medications with long half-lives. The reported relationship between higher maintenance doses of risperidone LAI and increased rates of EPS-related TEAEs ${ }^{13}$ raises concern that the use of a "loading dose" approach with paliperidone-LAI might increase the risk for EPS.

We conducted a pooled analysis of a comprehensive clinical trial data set in order to understand more clearly the incidence and time course of EPS-related TEAEs when initiating and continuing treatment with the paliperidone-LAI formulation. We compared these results with those observed on treatment with the oral paliperidone extended-release (ER) formulation. These posthoc analyses of data from the company-sponsored trials were designed to address four commonly encountered clinical questions associated with the initiation regimen of paliperidone-LAI:

- What is the time period when the highest incidence rates of EPS-related events are observed?

- Are EPS-related events dose-related?

- How do incidence rates of EPS-related events associated with paliperidone-LAI compare with those for oral paliperidone?

- Given the high doses used for the recommended initiation regimen, is the incidence of EPS-related events elevated during the first weeks of treatment with paliperidone-LAI relative to initiation of oral paliperidone?

\section{Materials and methods Clinical study selection}

Structuring the analyses to compare the EPS-related data across trials at specific time points after treatment initiation with paliperidone allowed us to assess any differences in EPSrelated events between the two paliperidone formulations. ${ }^{14-20}$ Studies of paliperidone that met the following criteria were included in the posthoc analysis: 1. studies sponsored by Janssen Research and Development (formerly Johnson and Johnson Pharmaceutical Research and Development); 2. multicenter, randomized, placebo-controlled, double-blind studies; 3 . assessed either oral paliperidone or paliperidoneLAI as the active treatment; 4 . used comparable doses for paliperidone (LAI studies, 25-150 mg eq.; oral studies, 3-15 mg); and 5. were conducted in patients with an acute exacerbation of previously diagnosed schizophrenia (defined by the Diagnostic and Statistical Manual of Mental Disorders, Fourth Edition) represented by a Positive and Negative Syndrome Scale (PANSS) total score of 70-120 inclusive, at screening. Open-label studies, active comparator studies without a placebo group, and Phase 1 studies were excluded from this analysis. Since access to patient level data was required for this analysis, non-company-sponsored studies were excluded.

Based on the above criteria, three oral paliperidone studies of 6 weeks' duration (pooled numbers: placebo, $n=355$; oral paliperidone, $n=963$ ) and four paliperidone-LAI studies of 9 to 13 weeks' duration (pooled numbers: placebo, $\mathrm{n}=510$; paliperidone-LAI, $\mathrm{n}=1293$ ) were identified (Table 1). The studies are already published in detail. ${ }^{14-20}$ All studies included in the posthoc analysis were adequately powered originally to assess efficacy (based on the change from baseline to endpoint in PANSS total score). Although safety was a secondary objective, the studies were not powered to detect any differences in safety outcomes, such as EPS rating scales or adverse event incidence rates.

An independent ethics committee or institutional review board at each study site approved the protocols of the studies included in this analysis. The studies were conducted in accordance with the ethical principles originating in the Declaration of Helsinki and International Conference on Harmonisation Good Clinical Practice guidelines, applicable regulatory requirements, and in compliance with the protocols. All patients (and their legally acceptable 
Table I Treatment schedule in the included paliperidone-LAl studies

\begin{tabular}{|c|c|c|c|c|c|c|}
\hline \multirow[t]{2}{*}{ Study } & \multirow{2}{*}{$\begin{array}{l}\text { Patients } \\
\text { randomized }(\mathrm{N})\end{array}$} & \multirow{2}{*}{$\begin{array}{l}\text { Randomization } \\
\text { schedule }^{\mathrm{a}}\end{array}$} & \multirow{2}{*}{$\begin{array}{l}\text { Injection } \\
\text { site }\end{array}$} & \multicolumn{2}{|c|}{ Initiation doses (mg eq.) } & \multirow{2}{*}{$\begin{array}{l}\text { Maintenance } \\
\text { doses (mg eq.) }\end{array}$} \\
\hline & & & & Day I & Day 8 & \\
\hline Pandina et $\mathrm{al}^{20}$ & 652 & I:I:I:I & Deltoid & 150 & 25,50 , or 100 & 25,50 , or 100 \\
\hline Kramer et al ${ }^{17}$ & 247 & $\mathrm{I}: \mathrm{I}: \mathrm{I}$ & Gluteal & 50 or 100 & 50 or 100 & 50 or 100 \\
\hline Gopal et al ${ }^{15}$ & 388 & I:I:I:I & Gluteal & 50,100 , or 150 & 50,100 , or 150 & 50,100 , or 150 \\
\hline Nasrallah et al ${ }^{19}$ & 518 & I:I:I:I & Gluteal & 25,50, or 100 & 25,50, or 100 & 25,50, or 100 \\
\hline
\end{tabular}

Notes: ${ }^{a} \mathrm{All}$ studies had a placebo arm as one of the randomization arms; because doses of paliperidone LAI can be expressed either in mg eq. of the pharmacologically active fraction, paliperidone, or in $\mathrm{mg}$ of paliperidone LAl, the doses expressed as 25,50 , I00, and I50 mg eq. equate to 39 , 78 , I56, and $234 \mathrm{mg}$, respectively, of paliperidone LAI.

Abbreviations: mg eq., milligram equivalents; LAI, long-acting injectable.

representatives, if required by local regulations) provided written informed consent.

\section{EPS-related safety parameters selected}

The safety parameters chosen were EPS severity as assessed using the Abnormal Involuntary Movement Scale (AIMS), Simpson-Angus Scale (SAS), and Barnes Akathisia Rating Scale (BARS) scores; incidences of spontaneously reported TEAE rates of Medical Dictionary for Regulatory Activities (MedDRA) preferred terms (version 11 or above) grouped under the prespecified categories of parkinsonism, tremor, dystonia, hyperkinesia, and dyskinesia; and the proportion of patients who used anti-EPS medications.

\section{EPS rating scales}

Investigators blinded to treatment assignment assessed EPS severity using EPS rating scale scores, consistent with standard clinical trial practice. ${ }^{21}$ The AIMS total scores were calculated to evaluate the presence and severity of dyskinesia by summing items 1 to 7 of the 12-item scale. ${ }^{22,23}$ The SAS total scores were calculated to evaluate the presence and severity of parkinsonism by summing items 1 to $10 .{ }^{23,24}$ Total score for BARS, rated from 0 to 3 , was calculated for drug-induced akathisia. ${ }^{25}$ In the oral paliperidone studies, assessments were completed one week before randomization and on days 1, 8, 15, 22, 29, 36, and 43. In three paliperidone-LAI studies, assessments were completed on days 1,8 , and 92 , and in the fourth LAI study, they were completed on days 1, 8, 15, 36, 43, and 64 .

\section{Treatment-emergent EPS}

Incidence rates of treatment-emergent EPS were assessed by rating scale scores at endpoint (ie, last visit in doubleblind phase: LAI studies, day 92; oral studies, day 43) and compared in patients in the paliperidone-LAI and oral paliperidone treatment groups for parkinsonism as the percentage of patients with an SAS total score $>0.3$, where the SAS total score was defined as the total sum of items score divided by the number of items; for akathisia as the percentage of patients with a BARS global clinical rating score $\geq 2$; and for dyskinesia as the percentage of patients with a score $\geq 3$ on any of the first seven items or a score $\geq 2$ on two or more of any of the first seven items of AIMS. Percentages were calculated based on number of patients in the safety analysis set per treatment group.

\section{Spontaneously reported EPS-related TEAEs}

The study analysis plans predefined EPS-related TEAEs using MedDRA preferred terms (version 11 or above). They were summarized by treatment groups, namely parkinsonism, tremor, dystonia, hyperkinesia, and dyskinesia (Table 2). Incidence rates of spontaneously reported EPS-related TEAEs were grouped by the time period of onset, ie, days 1-8, days 9-36, days 37-64, and day 64 onwards.

\section{Use of anti-EPS medication}

Anti-EPS medication use to treat emergent EPS is an indirect measure of clinically relevant EPS-related TEAEs. ${ }^{26}$ In this pooled analysis, it was calculated as the proportion of patients in each treatment group who had at least one dose of an anti-EPS medication (eg, trihexyphenidyl, benzatropine, biperiden) or an antihistamine with ancillary anticholinergic activity (eg, diphenhydramine, hydroxyzine) during the double-blind study period.

\section{Statistical analyses}

For the current analyses, pooled data from all patients in the safety analysis set (included all randomized and treated patients who received at least one dose during the double-blind phase) from paliperidone studies were included. Changes in scores from baseline in the AIMS, BARS, and SAS total scores are presented by treatment groups using descriptive statistics. Change from baseline to endpoint for 
Table 2 Categories of EPS-related adverse events: MedDRA preferred terms

\begin{tabular}{|c|c|}
\hline $\begin{array}{l}\text { EPS-related } \\
\text { AE subgroups }\end{array}$ & MedDRA preferred terms \\
\hline Tremor & Tremor, essential tremor, intention tremor \\
\hline Dystonia & $\begin{array}{l}\text { Oculogyration, oculogyric crisis, trismus, } \\
\text { tongue spasm, tongue paralysis, cervical spasm, } \\
\text { emprosthotonus, myotonia, pleurothotonus, risus } \\
\text { sardonicus, muscle spasms, blepharospasm, dystonia, } \\
\text { opisthotonus, torticollis, facial spasm, muscle } \\
\text { contracture }\end{array}$ \\
\hline Hyperkinesia & $\begin{array}{l}\text { Akathisia, hyperkinesia, periodic limb movement } \\
\text { disorder, restless legs syndrome, restlessness }\end{array}$ \\
\hline Parkinsonism & $\begin{array}{l}\text { Hypertonia, bradykinesia, cogwheel rigidity, drooling } \\
\text { musculoskeletal stiffness, akinesia, hypokinesia, } \\
\text { nuchal rigidity, Parkinsonian gait, Parkinsonian } \\
\text { rest tremor, parkinsonism, muscle rigidity, muscle } \\
\text { tightness, glabellar reflex abnormal, on and off } \\
\text { phenomenon, Parkinson's disease, Parkinsonian } \\
\text { crisis, extrapyramidal disorder, masked facies }\end{array}$ \\
\hline Dyskinesia & $\begin{array}{l}\text { Dyskinesia, muscle contractions involuntary, } \\
\text { movement disorder, muscle twitching, athetosis, } \\
\text { chorea, choreoathetosis, tardive dyskinesia, } \\
\text { myoclonus }\end{array}$ \\
\hline
\end{tabular}

Abbreviations: AE, adverse event; EPS, extrapyramidal symptoms; MedDRA, Medical Dictionary for Regulatory Activities.

each EPS rating scale scores were analyzed using an analysis of covariance (ANCOVA) model, with type of study (LAI versus oral) as factor and baseline score as covariate. The differences in least-square (LS) means (oral paliperidone group minus paliperidone-LAI group) and 95\% confidence intervals (CIs) were calculated for all three parameters. The incidences of spontaneously reported TEAEs grouped by time period of onset are presented by treatment group (LAI versus oral) in the pooled data using descriptive statistics. Graphic plots of the mean values for each EPS rating scale are plotted at each assessment time point by type of study (LAI versus oral) and dose group within each study type. To enable assessment of dose relationship to EPS, each dose group was plotted separately.

\section{Results}

\section{Demographic and clinical characteristics}

A total of 2256 antipsychotic-treated patients (paliperidoneLAI group, $n=1293$; oral paliperidone group, $n=963$ ) were included in the analysis. Demographic and baseline characteristics are provided in Table 3.

\section{EPS rating scale scores}

For both formulations, in all treatment groups, mean AIMS, BARS, and SAS total scores decreased from baseline to endpoint (Figure 1 and Supplementary Tables 1-3). Mean reductions from baseline to endpoint in EPS rating scale scores in the pooled paliperidone-LAI group (mean days of exposure, 45.4 [32.55]) were numerically larger than in the pooled oral paliperidone group (mean [SD] days of exposure, 33.3 [13.47]), Table 4. At individual study endpoints, the LS means difference between the groups was significant at the $5 \%$ level for the BARS $(P=0.023)$ and SAS $(P<0.0001)$ total score, but not for AIMS $(P=0.49)$. At day 43 , mean (SD) total BARS $(0.38$ [0.971] versus 0.4 [1.055]) and SAS scores $(0.11$ [0.232] versus $0.11[0.218])$ were comparable between paliperidone-LAI ( $\mathrm{n}=103$, one study) and oral paliperidone groups $(\mathrm{n}=603$, three studies); mean $(\mathrm{SD})$ AIMS total scores $(0.56$ [1.304] versus 0.43 [1.383]) were greater in paliperidone-LAI than in oral paliperidone group. Incidence rates of treatment-emergent EPS, as identified by EPS rating scale scores, were numerically lower in the paliperidone-LAI group than in the oral paliperidone group (Table 5).

\section{Spontaneously reported TEAEs}

The overall incidences of spontaneously reported EPSrelated TEAEs, and the total incidences in each category (except for hyperkinesia) were numerically lower in the pooled LAI studies than in the pooled oral studies (Table 6). The most frequently reported were parkinsonism and dyskinesia ( $\geq 5 \%$ of patients) in the oral paliperidone group and parkinsonism ( $\geq 2 \%$ of patients) in the paliperidone-LAI group. Numerically, the highest incidence of EPS-related TEAEs was observed between days 1 and 8 of treatment in the oral paliperidone (for all except parkinsonism and tremor, which had the highest incidence between days 9 and 36) and paliperidone-LAI (for all except dyskinesia which had the highest incidence between days 9 and 36) groups (Table 6).

\section{Use of anti-EPS medication}

At screening, anti-EPS medication usage was significantly higher $(P=0.0002)$ in the pooled paliperidone-LAI group (31\%) compared with the pooled oral paliperidone group (23\%). In contrast, during the double-blind phase, anti-EPS medication use was significantly lower $(P=0.0035)$ in the pooled paliperidone-LAI group (12\%; LAI placebo, $12 \%)$ versus the pooled oral paliperidone group (17\%; oral placebo, $10 \%)$. The most commonly used anti-EPS medication(s) $(>5 \%)$ in the pooled paliperidone-LAI group was benzatropine (8\%) and in the pooled oral paliperidone group were biperiden (7\%) and benzatropine (5\%). 
Table 3 Baseline demographics and clinical characteristics: pooled LAI studies versus pooled oral studies (safety analysis set)

\begin{tabular}{|c|c|c|c|c|}
\hline & $\begin{array}{l}\text { Paliperidone LAI } \\
(n=\mid 293)\end{array}$ & $\begin{array}{l}\text { Oral paliperidone } \\
(n=963)\end{array}$ & $\begin{array}{l}\text { LAI-PBO } \\
(n=5 \mid 0)\end{array}$ & $\begin{array}{l}\text { Oral-PBO } \\
(n=355)\end{array}$ \\
\hline Age (years), mean (SD) & $40(10.7)$ & $38(10.8)$ & $40(11.1)$ & $39(11.1)$ \\
\hline Men, n (\%) & $881(68)$ & $591(61)$ & $338(66)$ & $235(66)$ \\
\hline \multicolumn{5}{|l|}{ Race, n (\%) } \\
\hline White & $737(57)$ & $592(6 I)$ & $284(56)$ & $219(62)$ \\
\hline Black & $395(31)$ & $207(2 I)$ & $155(30)$ & $80(23)$ \\
\hline Asian & $138(\mathrm{II})$ & $88(9)$ & $64(13)$ & $29(8)$ \\
\hline Other & $23(2)$ & $76(8)$ & $7(1)$ & $27(8)$ \\
\hline Baseline PANSS total score, mean (SD) & $89(11.7)$ & $93(11.8)$ & $90(12.0)$ & 94 (II.7) \\
\hline Weight $(\mathrm{kg})$, mean $(\mathrm{SD})$ & $80(21.0)$ & $76(19.8)$ & $80(20.9)$ & $78(20.0)$ \\
\hline \multicolumn{5}{|l|}{ Schizophrenia type, n (\%) } \\
\hline Paranoid & II 33 (88) & $779(81)$ & $439(86)$ & $285(80)$ \\
\hline Disorganized & $25(2)$ & $39(4)$ & $12(2)$ & $14(4)$ \\
\hline Catatonic & $3(0.2)$ & $5(I)$ & $4(1)$ & 0 \\
\hline Residual & $9(1)$ & $20(2)$ & $7(1)$ & $7(2)$ \\
\hline Undifferentiated & $123(10)$ & $120(12)$ & $48(9)$ & $49(14)$ \\
\hline Age at diagnosis (years), mean (SD) & $25(8.4)$ & $26(8.5)$ & $26(8.7)$ & $26(9.6)$ \\
\hline Mean (SD) days of exposure & $45.4(32.55)$ & $33.3(13.47)$ & $35.3(31.42)$ & $28.4(13.66)$ \\
\hline \multicolumn{5}{|l|}{ Previous hospitalizations, n (\%) } \\
\hline 0 & $75(6)$ & $116(12)$ & $41(8)$ & $4 I(12)$ \\
\hline $1-3$ & $676(52)$ & $533(55)$ & $252(49)$ & $194(54)$ \\
\hline$\geq 4$ & $542(42)$ & $313(33)$ & $217(43)$ & $120(34)$ \\
\hline
\end{tabular}

Abbreviations: EPS, extrapyramidal symptoms; ER, extended-release; LAI, long-acting injectable; LAI-PBO, placebo group in LAI studies; Oral-PBO, placebo group in oral paliperidone studies; PANSS, Positive and Negative Syndrome Scale; SD, standard deviation.

\section{Discussion}

The goal of this posthoc descriptive analysis was to compare EPS-related safety data between studies of oral paliperidone and the paliperidone-LAI formulation. The results suggest that the "loading dose" initiation regimen for paliperidone-LAI does not lead to higher EPS rates compared with the oral ER formulation in patients with acute schizophrenia. Indeed, during maintenance treatment, EPS rates were generally numerically lower for the paliperidone-LAI formulation. Despite a two-fold longer follow-up time for the paliperidone-LAI group, the results support an overall advantage in terms of EPS rating scale scores and EPS-related TEAEs for paliperidone-LAI compared with oral paliperidone. This difference is supported by the greater reduction in total scores for AIMS, BARS and SAS, comparable mean rating scale scores, a numerically lower incidence of spontaneously reported EPS-related TEAEs and a lower percentage of patients using anti-EPS medication in the pooled paliperidone-LAI group versus the pooled oral paliperidone group. Rates of dystonia were notably lower for the LAI as compared with oral paliperidone (by nearly three-fold). These findings should be interpreted with caution because the difference could potentially be due to variations in the initiation regimens used in the earlier versus later LAI studies.
The consistent drop in the EPS rating scale (AIMS, BARS, SAS) scores from screening to baseline can potentially be explained by discontinuation of the previous antipsychotic and/or the withdrawal dyskinesia phenomenon. The EPS rating scale scores showed an overall improvement from screening to endpoint for all groups; the improvement statistically favoring LAI for BARS and SAS, but not AIMS. Overall, the means of these improvements in rating scale scores were comparable between the LAI and oral studies, without any evidence for a dose relationship. Despite greater prescreening use of anticholinergic medications and about $25 \%$ greater exposure during doubleblind treatment, fewer patients in the pooled studies using paliperidone-LAI required anti-EPS medication versus anticholinergic usage requirements in similar phases of the pooled oral studies.

Although the overall incidence of individual categories of EPS-related TEAEs was low (range 1\%-7\%) with both formulations, the overall incidence of all categories, except hyperkinesia, was numerically higher in the pooled oral paliperidone studies than in the pooled paliperidone-LAI studies despite less exposure in the pooled oral studies. For the most part, the highest incidence of EPS-related spontaneously reported TEAEs was seen as early as in the first week of paliperidone-LAI (for all except dyskinesia) 
and oral paliperidone treatment (for all except for parkinsonism and tremor). In the oral paliperidone studies, the incidence of tremor and parkinsonism was highest between days 9 and 36; however, the overall incidence was comparable with that observed between days 1 and 8. A low incidence of EPS-related TEAEs was observed in the LAI studies after day 43; the oral studies ended at this time point. The incidence of spontaneously reported TEAEs in this analysis generally corresponds well with the rating scale findings.
One hypothesis for potentially overall lower occurrence of EPS with paliperidone-LAI versus the oral formulation would be that, despite higher LAI initiation doses in the first week of treatment, the release rate leads to relatively lower plasma concentrations for comparable doses of paliperidoneLAI versus the oral formulation. A number of design features of the paliperidone-LAI studies could also help explain the lower incidence rate. In all of the Phase 2/3 efficacy studies for paliperidone-LAI, patients were required to have demonstrated tolerability to risperidone or paliperidone before

$\begin{array}{llllllllllllllllllllll}\text { A } & -7 & & -7 & 8 & 15 & 22 & 29 & 36 & 43 & 64 & 92 & -7 & 1 & 8 & 15 & 22 & 29 & 36 & 43 & 64 & 92\end{array}$

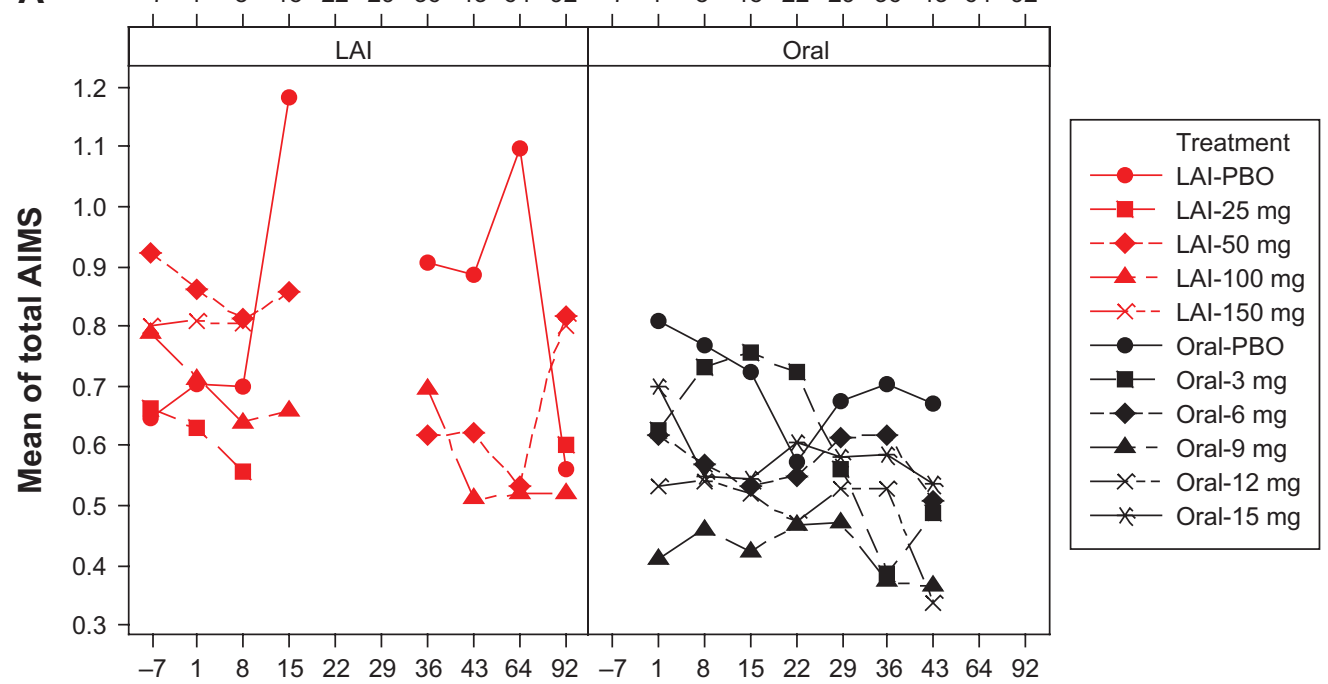

$\begin{array}{llllllllllllllllllllll}\text { B } & -7 & -7 & 1 & 8 & 15 & 22 & 29 & 36 & 43 & 64 & 92 & -7 & 1 & 8 & 15 & 22 & 29 & 36 & 43 & 64 & 92\end{array}$

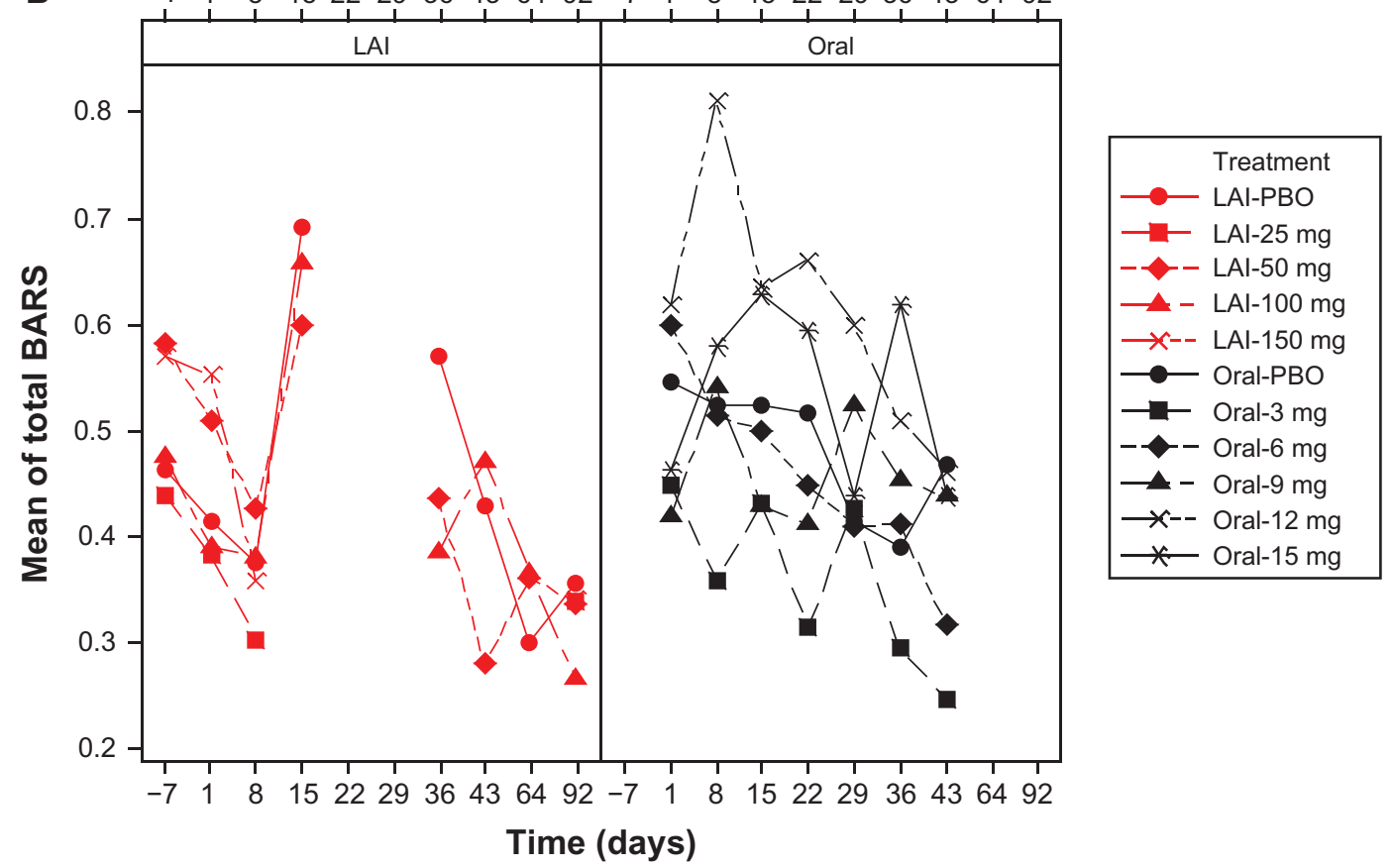

Figure I (Continued). 


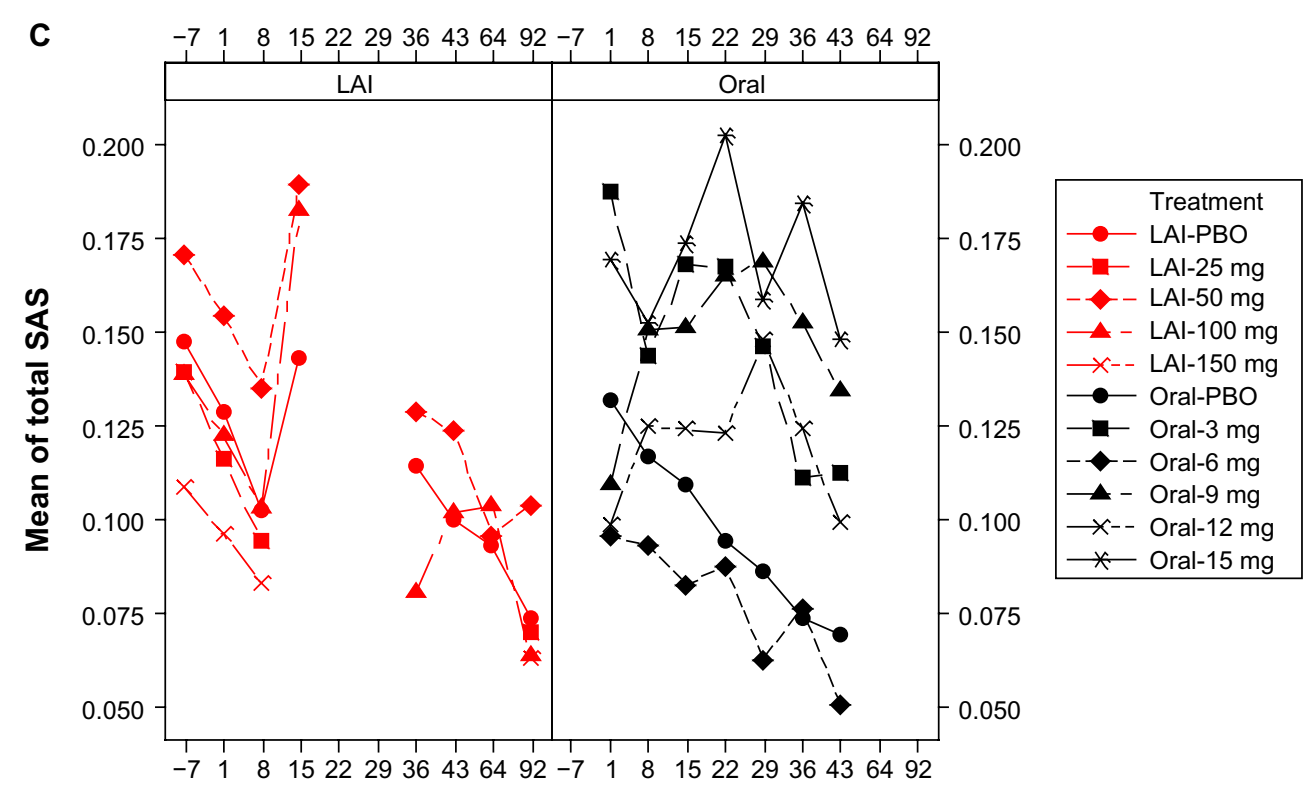

Time (days)

Figure I Mean EPS total scores over time by dose: pooled LAI versus oral paliperidone (safety analysis set). (A) Mean AIMS total scores, (B) mean BARS total scores, and (C) mean SAS total scores.

Notes: Doses of paliperidone-LAl shown are in mg eq.. Number of patients in each treatment (by dose) group changed over time. One LAI study, which included treatment groups of LAI placebo, LAI $50 \mathrm{mg}$ eq., and LAI I $00 \mathrm{mg}$ eq., had AIMS, BARS, and SAS measured at days -7, I, 8, I5, 36, 43, 64, and 92. The rest of the three LAI studies, which when combined included treatment groups of LAl placebo, LAI $25 \mathrm{mg}$ eq., LAl $50 \mathrm{mg}$ eq., LAl $100 \mathrm{mg}$ eq., and LAl $150 \mathrm{mg}$ eq., had AIMS, BARS, and SAS measured at days -7, I, 8, and 92 . Three oral studies, which when combined included treatment groups of oral placebo, $3 \mathrm{mg}, 6 \mathrm{mg}, 9 \mathrm{mg}, 12 \mathrm{mg}$, and I5 mg, had AIMS, BARS, and SAS measured at days I, 8 , I5, 22, 29, 36, and 43. LAI results for time points from days 15 to 64 are only from one study; data were not collected on day 22 and 29 in any of the LAl studies; hence the gaps in graphs.

Abbreviations: AIMS, Abnormal Involuntary Movement Scale; BARS, Barnes Akathisia Rating Scale; LAI, long-acting injectable; LAI-PBO, placebo group in LAI studies; mg eq, milligram equivalent; Oral-PBO, placebo group in oral studies; SAS, Simpson Angus Scale.

receiving an injection. Patients without documented evidence of tolerability were required to undergo a short period of tolerability testing with oral paliperidone for 2-7 days before the first injection in the double-blind phase. In clinical use, a similar oral tolerability testing is recommended for the
LAI formulation for those patients without prior exposure to risperidone or paliperidone.

The results of this comparison between oral paliperidone and paliperidone-LAI must be interpreted cautiously, in light of some important limitations. The original studies were not

Table 4 EPS rating scales total scores: pooled LAI studies versus pooled oral studies (safety analysis set)

\begin{tabular}{|c|c|c|c|c|}
\hline & $\begin{array}{l}\text { Paliperidone LAI } \\
\text { at I } 3 \text { weeks }\end{array}$ & $\begin{array}{l}\text { Oral paliperidone } \\
\text { at } 6 \text { weeks }\end{array}$ & LAI-PBO & Oral-PBO \\
\hline AIMS score, ${ }^{\mathrm{a}}$ mean $(\mathrm{SD})$ & $n=1269$ & $\mathrm{n}=946$ & $\mathrm{n}=497$ & $\mathrm{n}=34 \mathrm{I}$ \\
\hline Baseline & $0.75(1.916)$ & $0.55(1.578)$ & $0.7 \mathrm{I}(\mathrm{I} .8 \mathrm{I} 5)$ & $0.84(1.937)$ \\
\hline Change from baseline & $-0.10(1.27)$ & $-0.08(1.316)$ & $-0.08(1.365)$ & $-0.08(1.615)$ \\
\hline Difference of LSM ${ }^{\mathrm{b}}(95 \% \mathrm{Cl})$ & & $-0.04(-0.133,0.064)$ & & \\
\hline BARS score, ${ }^{a}$ mean $(S D)$ & $\mathrm{n}=1269$ & $\mathrm{n}=948$ & $\mathrm{n}=497$ & $\mathrm{n}=343$ \\
\hline Baseline & $0.45(1.104)$ & $0.52(1.239)$ & $0.71(1.815)$ & $0.56(1.160)$ \\
\hline Change from baseline & $-0.09(1.056)$ & $-0.03(1.237)$ & $-0.01(1.091)$ & $0.02(1.516)$ \\
\hline Difference of LSM ${ }^{\mathrm{b}}(95 \% \mathrm{Cl})$ & & $0.09(0.013,0.174)^{*}$ & & \\
\hline SAS scorea, mean (SD) & $\mathrm{n}=1260$ & $\mathrm{n}=939$ & $\mathrm{n}=494$ & $\mathrm{n}=337$ \\
\hline Baseline & $0.13(0.250)$ & $0.12(0.250)$ & $0.13(0.25 \mathrm{I})$ & $0.14(0.267)$ \\
\hline Change from baseline & $-0.04(0.200)$ & $0.0(0.229)$ & $-0.05(0.186)$ & $-0.04(0.186)$ \\
\hline Difference of LSM ${ }^{b}(95 \% \mathrm{Cl})$ & & $0.04(0.026,0.056)^{* *}$ & & \\
\hline
\end{tabular}

Notes: Endpoint was defined as the last visit in double-blind phase of LAl studies (day 92) and oral studies (day 43), thus length of exposure differs for the two treatments. ${ }^{2}$ Negative change in score indicates improvement. ${ }^{b}$ Difference of LSM represents oral paliperidone minus paliperidone LAI at endpoint; $* P=0.023 ; * * P<0.000 I$.

Abbreviations: AIMS, Abnormal Involuntary Movement Scale; BARS, Barnes Akathisia Rating Scale; Cl, confidence interval; EPS, extrapyramidal symptoms; LAI, long-acting injectable; LSM, least squares mean; PBO, placebo; SAS, Simpson Angus Rating Scale; SD, standard deviation; Oral-PBO, placebo group in oral paliperidone studies; LAI-PBO, placebo group in LAI studies. 
Table 5 Treatment-emergent EPS, as assessed by rating scale scores, in double-blind phase (safety analysis set)

\begin{tabular}{|c|c|c|c|c|}
\hline & $\begin{array}{l}\text { Paliperidone LAI } \\
(n=I 293) \\
n(\%)\end{array}$ & $\begin{array}{l}\text { Oral paliperidone } \\
(n=963) \\
n(\%)\end{array}$ & $\begin{array}{l}\text { LAI-PBO } \\
(n=5 \mid 0) \\
n(\%)\end{array}$ & $\begin{array}{l}\text { Oral-PBO } \\
(n=355) \\
n(\%)\end{array}$ \\
\hline Parkinsonism $^{\mathrm{a}}$ & $91(7)$ & $110(1 \mathrm{I})$ & $36(7)$ & $32(9)$ \\
\hline Akathisia $^{\mathrm{b}}$ & $55(4)$ & $66(7)$ & $23(5)$ & $22(6)$ \\
\hline Dyskinesiac $^{c}$ & $43(3)$ & $24(2)$ & $17(3)$ & $17(5)$ \\
\hline
\end{tabular}

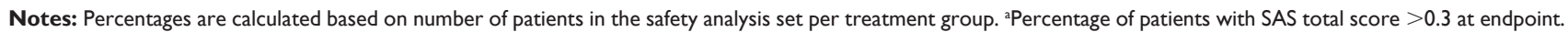
Total score was defined as (sum of items score)/(number of items); ${ }^{b}$ percentage of patients with BARS global clinical rating score $\geq 2$ at endpoint; ${ }^{c}$ percentage of patients with a score $\geq 3$ on any of the first seven items or a score $\geq 2$ on two or more of any of the first seven items of AIMS at endpoint.

Abbreviations: AIMS, Abnormal Involuntary Movement Scale; BARS, Barnes Akathisia Rating Scale; Cl, confidence interval; EPS, extrapyramidal symptoms; ER, extendedrelease; LAI, long-acting injectable; LAI-PBO, placebo group in LAI studies; LS Mean Diff, difference of least square means; Oral-PBO, placebo group in oral paliperidone studies; SAS, Simpson Angus Scale.

designed to detect differences in rates of EPS-related TEAEs between doses or groups, and the studies were done in different groups of countries at different times, which introduces other potential confounds. Although all LAI studies allowed treatment with oral paliperidone for several days as part of tolerability testing and also included two doses at initiation one week apart, only three of the four LAI studies (and only one arm of the fourth study) employed the currently recommended initiation dosing regimen (ie, $150 \mathrm{mg}$ eq. on day 1 and $100 \mathrm{mg}$ eq. on day 8). ${ }^{12}$ An additional limitation is that prior antipsychotic medication use was not controlled for and could have been different between the oral and LAI groups. In addition, factors that may moderate risk for experiencing EPS are not well understood. Family history of primary movement

Table 6 Incidence of spontaneously reported EPS-related treatment-emergent adverse events: pooled LAI versus oral (safety analysis set)

\begin{tabular}{|c|c|c|c|c|}
\hline & $\begin{array}{l}\text { Paliperidone LAl } \\
(\mathrm{n}=\mathrm{I} 293) \\
\mathrm{n}(\%)\end{array}$ & $\begin{array}{l}\text { Oral paliperidone } \\
(\mathrm{n}=963)^{\mathrm{b}} \\
\mathrm{n}(\%)\end{array}$ & $\begin{array}{l}\text { LAI-PBO } \\
(n=5 \mid 0) \\
n(\%)\end{array}$ & $\begin{array}{l}\text { Oral-PBO } \\
(n=355)^{b} \\
n(\%)\end{array}$ \\
\hline Overall & $138(10.7)$ & $191(19.8)$ & $46(9)$ & $39(11)$ \\
\hline Dystonia & $12(0.9)$ & $30(3.1)$ & I $(0.2)$ & $4(1.1)$ \\
\hline Day I-8 & $8(0.6)$ & $26(2.7)$ & 0 & $2(0.6)$ \\
\hline Day 9-36 & I $(0.1)$ & $9(0.9)$ & 0 & $2(0.6)$ \\
\hline Day 37-64 & $3(0.2)$ & $\mathrm{I}(0.1)$ & $\mathrm{I}(0.2)$ & 0 \\
\hline Day $>64$ & 0 & NA & 0 & NA \\
\hline Parkinsonism & $62(4.8)$ & $50(5.2)$ & $17(3.3)$ & $8(2.3)$ \\
\hline Day I-8 & $29(2.2)$ & $24(2.5)$ & $9(1.8)$ & $4(I .1)$ \\
\hline Day 9-36 & 24 (1.9) & $28(2.9)$ & $6(1.2)$ & $4(I .1)$ \\
\hline Day 37-64 & $9(0.7)$ & $4(0.4)$ & $2(0.4)$ & 0 \\
\hline Day $>64$ & $3(0.2)$ & NA & 0 & NA \\
\hline Tremor & $24(1.9)$ & $32(3.3)$ & $13(2.5)$ & $12(3.4)$ \\
\hline Day I-8 & $12(0.9)$ & $14(1.5)$ & $7(1.4)$ & $4(1.1)$ \\
\hline Day 9-36 & $10(0.8)$ & $15(1.6)$ & $5(1.0)$ & $8(2.3)$ \\
\hline Day 37-64 & $I(0.1)$ & $5(0.5)$ & $\mathrm{I}(0.2)$ & $2(0.6)$ \\
\hline Day $>64$ & $I(0.1)$ & NA & $\mathrm{I}(0.2)$ & NA \\
\hline Dyskinesia & $17(1.3)$ & $60(6.2)$ & $5(1.0)$ & $12(3.4)$ \\
\hline Day I-8 & $6(0.5)$ & $33(3.4)$ & $3(0.6)$ & $7(2.0)$ \\
\hline Day 9-36 & $9(0.7)$ & $32(3.3)$ & I (0.2) & $7(2.0)$ \\
\hline Day 37-64 & $\mathrm{I}(0.1)$ & $I(0.1)$ & $\mathrm{I}(0.2)$ & 0 \\
\hline Day $>64$ & $2(0.2)$ & NA & 0 & NA \\
\hline Hyperkinesia & $42(3.2)$ & $9(0.9)$ & $17(3.3)$ & $5(1.4)$ \\
\hline Day I-8 & $26(2.0)$ & $7(0.7)$ & $10(2.0)$ & I (0.3) \\
\hline Day 9-36 & $15(1.2)$ & $4(0.4)$ & $6(1.2)$ & $4(1.1)$ \\
\hline Day 37-64 & $4(0.3)$ & 0 & I $(0.2)$ & 0 \\
\hline Day $>64$ & $2(0.2)$ & NA & 0 & NA \\
\hline
\end{tabular}

Notes: Data for EPS-related TEAE were collected continuously during the studies. Time intervals shown were arbitrarily chosen to construct a frequency distribution. aFor three LAI studies, data were collected through day 92; for one LAl study data were collected through day 64; bfor all oral studies, data were collected through day 43; zero means no $A E$ with onset in this time interval.

Abbreviations: AE, adverse event; EPS, extrapyramidal symptoms; ER, extended-release; LAI, long-acting injectable; LAI-PBO, placebo group in LAI studies; NA, not assessed in this time interval; Oral-PBO, placebo group in oral paliperidone studies; TEAE, treatment-emergent adverse event. 
disorders, age, duration of antipsychotic exposure, and history of substance abuse, none of which were explored in this analysis, have all been suggested to increase EPS risk. ${ }^{27-29}$ Thus, this pooled EPS tolerability data cannot specify an individual patient's risk for developing EPS in clinical settings.

The schedule of assessment visits was similar in the oral and LAI studies included in this pooled analysis, except that EPS assessments were not collected on day 22 and 29 in any of the LAI studies and were collected for days 15, 36, 43, and 64 in only one LAI study. Another likely limitation could be that because EPS-related TEAE were categorized based on MedDRA terms, it was not possible to distinguish benign essential tremors from parkinsonian tremors, which may have very distinct clinical and physiologic implications. Such categorization also artificially separates parkinsonism from parkinsonian tremors, which are generally considered part of the same construct. For assessing use of anti-EPS medication, only anticholinergic and antihistamine medications were examined in this analysis. Other medications, such as beta-blockers and benzodiazepines, while commonly used to treat akathisia, are also used to treat other conditions, making it difficult to interpret the rate of use of these medications for treating EPS. Finally, this study does not address the severity of the EPS-related TEAEs examined and was not powered to address the issue of dose response.

A lower incidence of EPS-related TEAEs as observed in this study of paliperidone-LAI and in the studies with risperidone $\mathrm{LAI},{ }^{30-32}$ is important from the perspective of patient tolerability and long-term adherence with antipsychotic therapy. ${ }^{33}$ Having similar or lower EPS-related TEAEs and higher rates of adherence may encourage the use of LAI therapies and increase the overall adherence rates for patients with schizophrenia.

\section{Conclusion}

This posthoc descriptive analysis shows that incidence rates of spontaneously reported EPS-related TEAEs were generally numerically lower following approximately 90 days of exposure to paliperidone-LAI compared with approximately 40 days of exposure to oral paliperidone. These results further suggest that the loading dose initiation regimen for paliperidone-LAI does not lead to EPS rates higher than those associated with the oral extended-release ER formulation.

\section{Acknowledgment}

The authors thank the study participants, without whom the studies would never have been accomplished, and the investigators for their participation in these studies. ${ }^{14-20}$

\section{Author contributions}

$\mathrm{SG}, \mathrm{DH}, \mathrm{AS}$, and LA contributed to formulation of the research question and all of the authors contributed to the data interpretation. IN and YL contributed to the analysis and interpretation of the data of this study. All authors had access to the study data, provided direction and comments on the manuscript, made the final decision about where to publish these data, and read and approved the final manuscript for submission to this journal.

\section{Disclosure}

SG, YL, AS, IN, and DH are employees of Janssen Research and Development, LLC. LA is an employee of Janssen Scientific Affairs, LLC. All authors meet International Council of Medical Journal Editors criteria and all those who fulfilled those criteria are listed as authors. All the studies included in this analysis were funded by Janssen Research and Development, LLC, Raritan, NJ, USA. The sponsor also provided a formal review of the manuscript. We thank Madhoolika Nema and Lakshmi Venkatraman (SIRO Clinpharm Pvt Ltd) for providing writing assistance and Wendy P Battisti (Janssen Research and Development, LLC) for additional editorial support for this paper.

\section{References}

1. Shirzadi AA, Ghaemi SN. Side effects of atypical antipsychotics: extrapyramidal symptoms and the metabolic syndrome. Harv Rev Psychiatry. 2006;14:152-164.

2. Barnes TR, McPhillips MA. Novel antipsychotics, extrapyramidal side effects and tardive dyskinesia. Int Clin Psychopharmacol. 1998; 13 Suppl 3:S49-S57.

3. Leo RJ, Regno PD. Atypical antipsychotic use in the treatment of psychosis in primary care. Prim Care Companion J Clin Psychiatry. 2000;2:194-204.

4. Glazer WM. Extrapyramidal side effects, tardive dyskinesia, and the concept of atypicality. J Clin Psychiatry. 2000;61 Suppl 3:16-21.

5. Weiden PJ. EPS profiles: the atypical antipsychotics are not all the same. J Psychiatr Pract. 2007;13:13-24.

6. Ereshefsky L, Watanabe MD, Tran-Johnson TK. Clozapine: an atypical antipsychotic agent. Clin Pharm. 1989;8:691-709.

7. Kane JM, Fleischhacker WW, Hansen L, Perlis R, Pikalov A 3rd, Assuncao-Talbott S. Akathisia: an updated review focusing on second-generation antipsychotics. J Clin Psychiatry. 2009;70: 627-643.

8. Leucht S, Corves C, Arbter D, Engel RR, Li C, Davis JM. Secondgeneration versus first-generation antipsychotic drugs for schizophrenia: a meta-analysis. Lancet. 2009;373:31-41.

9. Miller CH, Mohr F, Umbricht D, Woerner M, Fleischhacker WW, Lieberman JA. The prevalence of acute extrapyramidal signs and symptoms in patients treated with clozapine, risperidone, and conventional antipsychotics. J Clin Psychiatry. 1998;59: 69-75.

10. Pierre JM. Extrapyramidal symptoms with atypical antipsychotics: incidence, prevention and management. Drug Saf. 2005;28:191-208.

11. Citrome L. Paliperidone palmitate - review of the efficacy, safety and cost of a new second-generation depot antipsychotic medication. Int $J$ Clin Pract. 2010;64:216-239. 
12. McCrea M, Pliskin N, Barth J, et al. Official position of the military TBI task force on the role of neuropsychology and rehabilitation psychology in the evaluation, management, and research of military veterans with traumatic brain injury. Clin Neuropsychol. 2008;22:10-26.

13. Simpson GM, Lindenmayer JP. Extrapyramidal symptoms in patients treated with risperidone. J Clin Psychopharmacol. 1997;17:194-201.

14. Davidson M, Emsley R, Kramer M, et al. Efficacy, safety and early response of paliperidone extended-release tablets (paliperidone ER): results of a 6-week, randomized, placebo-controlled study. Schizophr Res. 2007;93:117-130.

15. Gopal S, Hough DW, Xu H, et al. Efficacy and safety of paliperidone palmitate in adult patients with acutely symptomatic schizophrenia: a randomized, double-blind, placebo-controlled, dose-response study. Int Clin Psychopharmacol. 2010;25:247-256.

16. Kane J, Canas F, Kramer M, et al. Treatment of schizophrenia with paliperidone extended-release tablets: a 6-week placebo-controlled trial. Schizophr Res. 2007;90:147-161.

17. Kramer M, Litman R, Hough D, et al. Paliperidone palmitate, a potential long-acting treatment for patients with schizophrenia. Results of a randomized, double-blind, placebo-controlled efficacy and safety study. Int J Neuropsychopharmacol. 2010;13:635-647.

18. Marder SR, Kramer M, Ford L, et al. Efficacy and safety of paliperidone extended-release tablets: results of a 6-week, randomized, placebocontrolled study. Biol Psychiatry. 2007;62:1363-1370.

19. Nasrallah HA, Gopal S, Gassmann-Mayer C, et al. A controlled, evidence-based trial of paliperidone palmitate, a long-acting injectable antipsychotic, in schizophrenia. Neuropsychopharmacology. 2010;35: 2072-2082.

20. Pandina GJ, Lindenmayer JP, Lull J, et al. A randomized, placebocontrolled study to assess the efficacy and safety of 3 doses of paliperidone palmitate in adults with acutely exacerbated schizophrenia. J Clin Psychopharmacol. 2010;30:235-244.

21. Pope A, Adams C, Paton C, Weaver T, Barnes TR. Assessment of adverse effects in clinical studies of antipsychotic medication: survey of methods used. Br J Psychiatry. 2010;197:67-72.

22. Guy W. Abnormal Involuntary Movement Scale. In: Guy W, editor. ECDEU Assessment Manual for Psychopharmacology. Rockville, MD: US Dept of Health Education and Welfare; 1976.
23. Gervin M, Barnes TRE. Assessment of drug-related movement disorders in schizophrenia. Adv Psychiatr Treat. 2000;6:332-341.

24. Simpson GM, Angus JW. A rating scale for extrapyramidal side effects. Acta Psychiatr Scand Suppl. 1970;212:11-19.

25. Barnes TR. A rating scale for drug-induced akathisia. Br J Psychiatry. 1989;154:672-676

26. Gopal S, Berwaerts J, Nuamah I, et al. Number needed to treat and number needed to harm with paliperidone palmitate relative to longacting haloperidol, bromperidol, and fluphenazine decanoate for treatment of patients with schizophrenia. Neuropsychiatr Dis Treat. 2011;7: 93-101.

27. Potvin S, Blanchet P, Stip E. Substance abuse is associated with increased extrapyramidal symptoms in schizophrenia: a meta-analysis. Schizophr Res. 2009;113:181-188.

28. Kasten M, Bruggemann N, Konig IR, et al. Risk for antipsychotic-induced extrapyramidal symptoms: influence of family history and genetic susceptibility. Psychopharmacology (Berl). 2011;214:729-736.

29. Lencer R, Eismann G, Kasten M, et al. Family history of primary movement disorders as a predictor for neuroleptic-induced extrapyramidal symptoms. Br J Psychiatry. 2004;185:465-471.

30. Chue P, Eerdekens M, Augustyns I, et al. Comparative efficacy and safety of long-acting risperidone and risperidone oral tablets. Eur Neuropsychopharmacol. 2005;15:111-117.

31. Emsley R, Medori R, Koen L, Oosthuizen PP, Niehaus DJ, Rabinowitz J. Long-acting injectable risperidone in the treatment of subjects with recent-onset psychosis: a preliminary study. J Clin Psychopharmacol. 2008;28:210-213.

32. Moller HJ. Long-acting injectable risperidone for the treatment of schizophrenia: clinical perspectives. Drugs. 2007;67:1541-1566.

33. Olivares JM, Rodriguez-Morales A, Diels J, et al. Long-term outcomes in patients with schizophrenia treated with risperidone long-acting injection or oral antipsychotics in Spain: results from the electronic Schizophrenia Treatment Adherence Registry (e-STAR). Eur Psychiatry. 2009;24:287-296. 


\section{Supplementary tables}

Table SI Mean Abnormal Involuntary Movement Scale total score (standard deviation) over time by treatment group: safety analysis set

\begin{tabular}{|c|c|c|c|c|c|c|c|c|c|c|}
\hline Time (days) & -7 & I & 8 & 15 & 22 & 29 & 36 & 43 & 64 & 92 \\
\hline LAI PBO & $0.6(1.64)$ & $0.7(\mathrm{I} .8)$ & $0.7(1.96)$ & I.2(2.8I) & - & - & $0.9(1.91)$ & $0.9(1.53)$ & I.I (2.7) & $0.6(1.53)$ \\
\hline LAI 25 mg & 0.7 (I.87) & $0.6(1.78)$ & $0.6(1.6)$ & - & - & - & - & - & - & $0.6(1.8)$ \\
\hline LAI 50 mg & $0.9(2.13)$ & $0.9(1.93)$ & $0.8(1.88)$ & $0.9(1.76)$ & - & - & $0.6(1.42)$ & $0.6(1.47)$ & $0.5(I .4 I)$ & $0.8(1.86)$ \\
\hline LAI 100 mg & $0.8(1.93)$ & $0.7(1.75)$ & $0.6(1.74)$ & $0.7(1.55)$ & - & - & $0.7(2.17)$ & $0.5(1.14)$ & $0.5(1.28)$ & $0.5(1.47)$ \\
\hline LAI I50 mg & $0.8(2.37)$ & $0.8(2.29)$ & $0.8(2.17)$ & - & - & - & - & - & - & $0.8(2.38)$ \\
\hline Oral PBO & - & 0.8 (I.9I) & $0.8(1.98)$ & 0.7 (I.79) & $0.6(1.59)$ & $0.7(\mathrm{I} .8 \mathrm{I})$ & 0.7 (I.79) & $0.7(1.63)$ & - & - \\
\hline Oral 3 mg & - & $0.6(1.59)$ & $0.7(1.86)$ & $0.8(2.04)$ & 0.7 (1.88) & $0.6(1.65)$ & $0.4(1.14)$ & $0.5(1.4)$ & - & - \\
\hline Oral $6 \mathrm{mg}$ & - & $0.6(I .7 I)$ & $0.6(1.53)$ & $0.5(1.49)$ & $0.5(1.38)$ & $0.6(1.44)$ & $0.6(1.55)$ & $0.5(1.42)$ & - & - \\
\hline Oral 9 mg & - & $0.4(1.27)$ & $0.5(\mathrm{I} .5 \mathrm{I})$ & 0.4 (I.I4) & $0.5(1.32)$ & $0.5(I . I)$ & $0.4(1.07)$ & $0.4(1.03)$ & - & - \\
\hline Oral 12 mg & - & $0.5(1.55)$ & $0.5(1.43)$ & $0.5(1.47)$ & $0.5(1.38)$ & $0.5(1.54)$ & $0.5(1.75)$ & $0.3(1.4)$ & - & - \\
\hline Oral 15 mg & - & $0.7(1.86)$ & $0.5(1.56)$ & $0.5(1.73)$ & $0.6(1.67)$ & $0.6(1.57)$ & $0.6(1.7)$ & $0.5(1.83)$ & - & - \\
\hline Oral OLZ & - & $0.6(1.79)$ & $0.6(\mathrm{I} .58)$ & 0.5 (I.39) & $0.4(1.33)$ & $0.3(1.08)$ & $0.4(1.35)$ & $0.3(1.26)$ & - & - \\
\hline
\end{tabular}

Abbreviations: LAI, long-acting injectable; OLZ, olanzapine; PBO, placebo.

Table S2 Mean Barnes Akathisia Rating Scale total score (standard deviation) over time by treatment group: safety analysis set

\begin{tabular}{|c|c|c|c|c|c|c|c|c|c|c|}
\hline Time (days) & -7 & I & 8 & 15 & 22 & 29 & 36 & 43 & 64 & 92 \\
\hline LAI PBO & $0.5(1.15)$ & $0.4(1.08)$ & $0.4(1.02)$ & $0.7(I .3 \mathrm{I})$ & - & - & $0.6(1.15)$ & $0.4(0.95)$ & $0.3(0.7)$ & $0.4(1.04)$ \\
\hline LAI 25 mg & $0.4(1.19)$ & $0.4(1.09)$ & $0.3(I)$ & - & - & - & - & - & - & $0.3(1.05)$ \\
\hline LAI 50 mg & $0.6(1.29)$ & $0.5(1.18)$ & $0.4(\mathrm{I} .0 \mathrm{I})$ & $0.6(1.23)$ & - & - & $0.4(0.92)$ & $0.3(0.83)$ & $0.4(0.92)$ & $0.3(0.98)$ \\
\hline LAI 100 mg & $0.5(1.05)$ & $0.4(0.99)$ & $0.4(1.05)$ & $0.7(I .3 I)$ & - & - & $0.4(0.94)$ & 0.5 (1.09) & $0.4(0.89)$ & $0.3(0.9)$ \\
\hline LAI I50 mg & $0.6(1.24)$ & $0.6(1.2)$ & $0.4(1.01)$ & - & - & - & - & - & - & $0.3(1.11)$ \\
\hline Oral PBO & - & 0.5 (I.15) & $0.5(\mathrm{I} . \mathrm{I} 2)$ & $0.5(1.14)$ & $0.5(1.28)$ & $0.4(1.05)$ & $0.4(1.04)$ & 0.5 (I.28) & - & - \\
\hline Oral 3 mg & - & 0.4 (1.07) & $0.4(\mathrm{I} .12)$ & $0.4(1.26)$ & $0.3(0.98)$ & $0.4(1.14)$ & $0.3(0.88)$ & $0.2(0.74)$ & - & - \\
\hline Oral $6 \mathrm{mg}$ & - & $0.6(1.46)$ & 0.5 (I.27) & $0.5(1.09)$ & 0.4 (I.II) & $0.4(1.06)$ & $0.4(1.03)$ & $0.3(0.97)$ & - & - \\
\hline Oral 9 mg & - & $0.4(1.1)$ & $0.5(1.15)$ & $0.4(I)$ & $0.4(0.94)$ & $0.5(1.07)$ & $0.5(I . I)$ & $0.4(1.09)$ & - & - \\
\hline Oral 12 mg & - & $0.6(1.29)$ & $0.8(1.55)$ & $0.6(1.42)$ & $0.7(\mathrm{I} .4)$ & $0.6(1.34)$ & $0.5(1.24)$ & $0.5(1.2)$ & - & - \\
\hline Oral I5 mg & - & $0.5(1.06)$ & $0.6(I . I 4)$ & $0.6(1.24)$ & $0.6(I .14)$ & $0.4(1.06)$ & $0.6(1.29)$ & $0.4(1.06)$ & - & - \\
\hline Oral OLZ & - & $0.5(1.14)$ & 0.5 (I.22) & $0.3(0.95)$ & $0.3(0.98)$ & $0.3(I)$ & $0.2(0.86)$ & $0.3(0.72)$ & - & - \\
\hline
\end{tabular}

Abbreviations: LAI, long-acting injectable; OLZ, olanzapine; PBO, placebo.

Table S3 Mean Simpson Angus Rating Scale total score (standard deviation) over time by treatment group: safety analysis set

\begin{tabular}{|c|c|c|c|c|c|c|c|c|c|c|}
\hline Time (days) & -7 & I & 8 & 15 & 22 & 29 & 36 & 43 & 64 & 92 \\
\hline LAI PBO & $0.1(0.3)$ & $0.1(0.25)$ & $0.1(0.22)$ & $0.1(0.25)$ & - & - & $0.1(0.23)$ & $0.1(0.2)$ & $0.3(0.7)$ & $0.4(1.04)$ \\
\hline LAI 25 mg & $0.1(0.28)$ & $0.1(0.25)$ & $0.1(0.2)$ & - & - & - & - & - & - & $0.3(1.05)$ \\
\hline LAI 50 mg & $0.2(0.3)$ & $0.2(0.28)$ & $0.1(0.26)$ & $0.2(0.35)$ & - & - & $0.1(0.26)$ & $0.1(0.24)$ & $0.4(0.92)$ & $0.3(0.98)$ \\
\hline LAI 100 mg & $0.1(0.26)$ & $0.1(0.25)$ & $0.1(0.21)$ & $0.2(0.32)$ & - & - & $0.1(0.21)$ & $0.1(0.22)$ & $0.4(0.89)$ & $0.3(0.9)$ \\
\hline LAI I50 mg & $0.1(0.23)$ & $0.1(0.21)$ & $0.1(0.19)$ & - & - & - & - & - & - & $0.3(\mathrm{I} . \mathrm{II})$ \\
\hline Oral PBO & - & $0.1(0.26)$ & $0.1(0.26)$ & $0.1(0.26)$ & $0.1(0.24)$ & $0.1(0.22)$ & $0.1(0.2)$ & $0.1(0.2 \mathrm{I})$ & - & - \\
\hline Oral 3 mg & - & $0.2(0.34)$ & $0.1(0.3)$ & $0.2(0.35)$ & $0.2(0.36)$ & $0.1(0.28)$ & $0.1(0.23)$ & $0.1(0.24)$ & - & - \\
\hline Oral $6 \mathrm{mg}$ & - & $0.1(0.18)$ & $0.1(0.19)$ & $0.1(0.16)$ & $0.1(0.18)$ & $0.1(0.14)$ & $0.1(0.15)$ & $0.1(0.11)$ & - & - \\
\hline Oral 9 mg & - & $0.1(0.21)$ & $0.2(0.28)$ & $0.2(0.27)$ & $0.2(0.28)$ & $0.2(0.3)$ & $0.2(0.26)$ & $0.1(0.24)$ & - & - \\
\hline Oral $12 \mathrm{mg}$ & - & $0.1(0.23)$ & $0.1(0.27)$ & $0.1(0.25)$ & $0.1(0.26)$ & $0.1(0.28)$ & $0.1(0.25)$ & $0.1(0.19)$ & - & - \\
\hline Oral $15 \mathrm{mg}$ & - & $0.2(0.33)$ & $0.2(0.29)$ & $0.2(0.35)$ & $0.2(0.37)$ & $0.2(0.29)$ & $0.2(0.3 \mathrm{I})$ & $0.1(0.29)$ & - & - \\
\hline Oral OLZ & - & $0.1(0.27)$ & $0.1(0.24)$ & $0.1(0.2)$ & $0.1(0.2)$ & $0.1(0.2 I)$ & $0.1(0.18)$ & $0.1(0.18)$ & - & - \\
\hline
\end{tabular}

Abbreviations: LAI, long-acting injectable; OLZ, olanzapine; PBO, placebo. 


\section{Publish your work in this journal}

Neuropsychiatric Disease and Treatment is an international, peerreviewed journal of clinical therapeutics and pharmacology focusing on concise rapid reporting of clinical or pre-clinical studies on a range of neuropsychiatric and neurological disorders. This journal is indexed on PubMed Central, the 'PsycINFO' database and CAS.

The manuscript management system is completely online and includes a very quick and fair peer-review system, which is all easy to use. Visit http://www.dovepress.com/testimonials.php to read real quotes from published authors.

\footnotetext{
Submit your manuscript here: http://www.dovepress.com/neuropsychiatric-disease-and-treatment-journal
} 